\title{
ETIMOLOGÍAS DEL ESPAÑOL AMERICANO
}

\author{
Mario Portilla
}

\section{(c) $(7)$}

Esta obra está bajo una licencia Creative Commons

Reconocimiento-No Comercial-Sin Obra Derivada 



\title{
ETIMOLOGÍAS DEL ESPAÑOL AMERICANO
}

\author{
ETIMOLOGIES IN THE AMERICAN SPANISH
}

Mario Portilla

\begin{abstract}
RESUMEN
El tratamiento de las etimologías del español americano en los diccionarios, tanto regionales como generales, muestra un descuido y una falta de interés por parte de los investigadores de la lexicografía hispanoamericana. Por ello, la indagación etimológica en este campo parece ser prometedora, aunque no exenta de dificultades. En este artículo, se presenta un proyecto en curso sobre las etimologías del español de Costa Rica, que constituye una primera etapa de una investigación mayor que incluirá el estudio etimológico del español de América Central. Finalmente, esta investigación contribuirá al esclarecimiento de etimologías del español general americano.

Palabras clave: etimología, lexicografía, español de Costa Rica, español de América Central, español americano.
\end{abstract}

\begin{abstract}
The treatment of etimologies in the American Spanish in regional and general dictionaries shows carelessness and lack of interest by the researchers of Hispanic American lexicography. That is why the etimological research in this area is promising albeit difficult. This article presents an ongoing project about Spanish etimologies in Costa Rica, the first stage of a larger etimological study of Central American Spanish. Finally, this research will contribute to the understanding of etimologies of American Spanish in general.

Key words: Etimology, Lexicography, Costa Rican Spanish, Central American Spanish, American
\end{abstract} Spanish.

\section{Introducción}

El establecimiento de etimologías en los diccionarios del español se remonta al origen mismo de la lexicografía hispánica. En su Tesoro de la lengua castellana de 1611, que constituye el primer diccionario monolingüe del español, Covarrubias presenta información etimológica

Dr. Mario Portilla. Universidad de Costa Rica. Profesor Catedrático. Escuela de Filología y Lingüística. Director del Instituto de Investigaciones Lingüísticas. Costa Rica.

Correo electrónico: mportillacr@yahoo.com

Recepción: 01- 11- 2014

Aceptación: 28- 11- 2014 
para gran parte de sus entradas. El Diccionario de Autoridades de la Real Academia Española (1726-1739), el cual estuvo basado en buena medida en diccionario de Covarrubias, también ofrece referencias etimológicas para gran cantidad de lemas. El Diccionario de la Real Academia incluirá indicaciones sobre el origen de las palabras apenas a partir de la duodécima edición de 1884.

Es interesante destacar que, en el mencionado Tesoro de la lengua castellana, Sebastián Covarrubias presenta referencias etimológicas para ya reconocidos aportes léxicos de origen indígena americano, iniciando con ello la indagación etimológica de los llamados americanismos. El siguiente es un ejemplo que corresponde al primer americanismo consignado en la lexicografía hispánica, canoa, el cual fue recogido por primera vez en el Vocabulario español - latino de Antonio de Nebrija (hacia 1495) ['Canoa nave de un madero. monofylum.i.'].

\begin{abstract}
CANOA, es varco hecho ordinariamente de vna pieça como artesa de que vsan los Indios, y ellos llaman a estas varquillas en su lengua Atlacales, q' vale tanto como casas de agua, porque en algunas partes viuen en ellas dentro de las lagunas, por assegurarse de enemigos, y de fieras de la tierra. Es nombre compuesto de Atl, que vale agua, y calli, casa, y todo junto casas de agua. Esto es en lengua Mexicana: mas porque a tales varquillas las llaman en Santo Domingo, donde primero estuuieron los Españoles Canoas, las llamaron a todas de este nombre. Los nuestros afirmã auer en solo Mexico mas de cinquenta mil dellas, con que portean gentes, y traen bastimentos. (Nebrija, 1951 [1494])
\end{abstract}

Los diccionarios contrastivos del español, los generales de americanismos o los de regionalismos particulares no han sido consistentes en la tarea de señalar etimologías. Los primeros diccionarios de americanismos, el Diccionario de voces americanas atribuido a Manuel José de Ayala, redactado entre 1750 y 1777, y el Diccionario histórico geográfico de las Indias Occidentales ó América de Antonio de Alcedo, publicado entre 1786 y 1789, no contienen etimologías de los vocablos recogidos. Los diccionarios de regionalismos tanto americanos como peninsulares redactados durante el siglo XIX tampoco suelen establecer etimologías para los vocablos. Ni el primer diccionario de 'provincialismos' americanos, el Diccionario provincial de voces cubanas de Esteban Pichardo, publicado en 1836, ni el Ensayo de un diccionario aragonés-castellano de Pedro José Gelabert, publicado en 1853, por ejemplo, presentan referencias etimológicas en las entradas comprendidas en ellos. ${ }^{1}$

Por otra parte, otros diccionarios de regionalismos americanos de finales de este siglo sí hacen algunas referencias al origen de las palabras tratadas. Tal es el caso de la obra Vicios del lenguaje y provincialismos de Guatemala de Antonio Batres Jáuregui, de 1892, y el Diccionario de barbarismos y provincialismos de Carlos Gagini, de 1893.

Un ejemplo tomado de la obra de Antonio Batres es el siguiente:

Amol. Es una planta venenosa, que se usa para pescar, y que mata todos los peces grandes y chicos [...] En lengua mexicana se llama ese tósigo AMOLE, nombre que se conservó hasta el siglo XVII. (Batres, 1896, pp. 90-91)

Otro ejemplo extraído esta vez del Diccionario de Gagini es el siguiente:

Achará. Ignoramos el origen de esta expresiva interjección costarricense, equivalente en castellano à ¡qué lástima! ¿Tendrá relación con el verbo andaluz hacharar? (Gagini, 1893, p. 19)

Las referencias etimológicas son muy escasas, se presentan de manera asistemática y corresponden más bien a información de tipo enciclopédico. En ningún caso, es la intención de los autores establecer de manera metódica las etimologías de los vocablos que presentan. Las referencias etimológicas aparecen casi como una acotación histórica o etnográfica. 
Así, por ejemplo, en la entrada correspondiente al lema adifesio, Gagini refiere distintas historias que explicarían la causa que lleva al sentido de 'despropósito' o 'cosa ridícula' que tiene el vocablo en su forma estándar adefesio, según varias fuentes. Sin embargo, al final declara a modo de disculpa: "Todo esto es para nosotros hablar ad ephesios, pues aquí no nos compete inquirir el origen del vocablo: solamente queríamos insinuar que no se dice adifesio sino adefesio." (Gagini, 1893, p. 20).

Finalmente, otra cita ejemplifica el valor histórico-etnográfico de las referencias etimológicas en esta obra de Gagini.

\begin{abstract}
Agora. Burlábase de nuestros labriegos un extranjero petulante porque dicen agora en lugar de ahora: según él, era ésta una de las más graciosas corruptelas que había oído en Costa Rica; pero el pobre se quedó como quien ve visiones cuando le mostramos los siguientes versos de Garcilaso: 'Do están agora aquellos claros ojos/ que llevaban tras sí como colgada/ mi ánima doquier que se volvían?' Agora (del latín hac hora, en esta hora) es una palabra castellana que se arrumbó en el siglo pasado. Todavía es de uso común entre los campesinos españoles. (Gagini, 1893, p. 24)
\end{abstract}

También, los diccionarios generales del español de América así como los regionales elaborados hasta la década de los setenta del siglo XX suelen contener algún tipo de información etimológica. Dos ejemplos de estos diccionarios son el Diccionario de americanismos de Marcos A. Morínigo de 1966 y el Diccionario de costarriqueñismos de Arturo Agüero, publicado en 1996, pero iniciado en la década de los años sesenta.

A partir de los años ochenta del siglo XX, tanto los diccionarios generales de americanismos como los particulares de los distintos países, al decantarse más exclusivamente por la corriente sincrónica, no suelen ofrecer información etimológica. Dos ejemplos de esta modalidad son el Diccionario de hispanoamericanismos no recogidos por la Real Academia de Renaud Richard de 1997 y Diccionario de venezolanismos de Tejera de 1993.

Esta tendencia es confirmada por Milagros Aleza-Izquierdo (2000, pp. 36-37) para varios diccionarios de americanismos publicados en la década de los noventa del siglo pasado.

Una de las novedades que presentan estos diccionarios es la de no incluir indicaciones sobre el origen de las palabras, dado el caos que en la lexicografía tradicional ha producido el intento de indicar el origen, sobre todo, de aquellas voces que no son españolas (aunque el origen latino, griego y árabe también se solía marcar). Ninguno de los diccionarios que estamos revisando (NDA [Nuevo Diccionario de Americanismos: Colombia], DHAV [Diccionario del habla actual de Venezuela], NDC [Nuevo Diccionario de Costarriqueñismos]) incluye etimología ni información sobre el origen del lema.

Precisamente, la dificultad que plantea el esclarecimiento de muchos étimos de los llamados americanismos históricos es lo que ha sido aducido, por lo general, para justificar no incluir etimologías en los diccionarios más modernos del español de América (cf. FajardoAguirre, 2010, pp. 346-347).

Esta posición es expresada claramente por Haensch (2000, pp. 180-181):

\footnotetext{
Algunos colegas han criticado o por lo menos lamentado, el hecho de que en los diccionarios del "Proyecto Ausburgo" no se hayan indicado etimologías. Esto, en primer lugar, no es necesario ni usual en un diccionario descriptivo que tiene otra finalidad; en segundo lugar, me gustaría que alguien me explicara dónde hay especialistas en docenas de lenguas amerindias, que conozcan al mismo tiempo la evolución histórica de éstas y la gramática histórica del español, para investigar los casos de las etimologías amerindias no resueltos hasta hoy; todo ello ante la falta de un número suficiente de estudios de documentos y relatos desde el Descubrimiento hasta el siglo XIX.
}

Resulta significativo, sin embargo, que el Diccionario de americanismos de la Asociación de Academias de la Lengua Española de 2010 contenga referencias etimológicas, 
siguiendo con la tradición lexicográfica académica, aunque ciertamente lo haga solo de manera selectiva. En la "Guía del consultor" se indica lo siguiente acerca de la información etimológica contenida en el diccionario: "Llevan información etimológica los lemas que la necesiten para su mejor comprensión, sobre todo los que no sean de procedencia patrimonial española" (Asociación de Academias de la Lengua Española, 2010, p. xi).

El recuento del tratamiento de las etimologías en los diccionarios del español americano indica que este ha sido un campo de estudio que ha sido descuidado, especialmente en la actualidad. La aparente dificultad en establecer el origen preciso de ciertos vocablos ha sido aducida como la justificación principal de obviar la indagación etimológica.

Además, en general, los diccionarios descriptivos que no contemplan la perspectiva etimológica enfrentan el problema de la homonimia simplemente ignorándola.

Sobre este asunto, en la introducción de su Diccionario de hispanoamericanismos no recogidos por la Real Academia, Renaud Richard expresa: "Cabe precisar al respecto que en nuestro trabajo, los homónimos no dan lugar a entradas especiales: el grupo prefirió no abordar las etimologías (tan inseguras y discutidas) de las formas y locuciones presentadas" (Richard, 1997-2006, p. 10).

\section{El tratamiento de las etimologías}

Ciertamente, se debe reconocer que el tratamiento de las etimologías de muchos vocablos considerados americanismos no ha sido acertado.

En primer lugar, tenemos el caso de los diccionarios generales del español que incluyen usos americanos. Esta falta de rigurosidad en el tratamiento de las etimologías puede ser ilustrada con el siguiente ejemplo tomado del Diccionario de la Real Academia Española. El vocablo gato aparece especificado en tres lemas distintos:

Gato' ${ }^{1}$. (Del latín cattus)

1. m. Mamífero carnívoro de la familia de los Félidos, digitígrado, doméstico [...]

2. $\mathrm{m}$. Bolso o talego en que se guardaba el dinero [...]

6. m. Trampa para coger ratones [...]

8. m. coloq. Ladrón, ratero que hurta con astucia y engaño.

9. m. coloq. Hombre sagaz, astuto [...]

12. m. Zool. Nombre aplicado a todos los félidos en general.

13. m. Arg. y Ur. Baile de movimientos rápidos, de pareja suelta [...]

14. m. Arg. Música que acompaña ese baile.

15. m. C Rica. Variedad de pastel, cortado rectangularmente, compuesto de dos tapas unidas con miel o conserva [...]

16. m. El Salv. bíceps braquial.

17. m. despect. coloq. El Salv. y Méx. servidor (II persona que sirve como criado).

Gato $^{2}$. (Del quechua qhatu, mercado)

1. m. Perú Mercado al aire libre.

Gato $^{3}$, ta. $\left(\right.$ Del gato $\left.{ }^{1}\right)$

1. adj. C. Rica y Nic. Dicho de una persona: Que tiene los ojos verdes o azules.

El término gato ${ }^{1}$ incluye 17 acepciones distintas como definiciones del mismo lema. Las definiciones del 1 al 12 aparecen sin marcación alguna o con indicación del registro de uso. Se trata, pues, o bien de significados generales del español actual o bien de usos no vigentes, pero históricos del español, especialmente europeo. 
En el ejemplo citado, la acepción número 2, 'bolso o talego', aunque en principio no sea tan clara su relación con el significado primario, se vuelve etimológicamente transparente al descubrir que estos bolsos eran hechos comúnmente con la piel de este animal. Se trata de una metonimia: el bolso está hecho de piel, la piel es de gato, por tanto, el bolso es el gato. Las acepciones 6,8,9 se derivan del significado primario del término como casos de claras metáforas relacionadas con cualidades o hábitos atribuidos a este animal. La acepción 12 constituye otro ejemplo de una metonimia (un gato es un tipo de felino, por tanto, todo felino es un gato).

Las definiciones de 13 a 17 constituyen usos americanos. La acepción 13 tampoco es transparente en cuanto a su etimología. Sin embargo, se trata de otro proceso metonímico. El nombre de este baile, popularizado en América del Sur a partir del siglo XIX, especialmente en Argentina, proviene del estribillo de una copla que se cantaba al compás de la música con que se ejecutaba esta danza: "Salta la perdiz madre I salta la infeliz I que se la lleva el gato I el gato mis-mis." (Furt, 1927, p. 42). Este origen etimológico está corroborado por el hecho de que este baile ha sido conocido en las pampas rioplatenses también como perdiz y como mis-mis (Furt, 1927, p. 43).

La acepción 14 es otro ejemplo de una metonimia: el baile se ejecuta con cierta música, por tanto, esa música es llamada como el baile.

La acepción 16 constituye también un caso de metonimia. Es probable que el término gato, en El Salvador, para referirse al bíceps braquial sea una metonimia humorística, pues en Costa Rica, por ejemplo, se llama ratón al bíceps. Es decir, la metonimia jocosa consiste en llamar 'gato' al 'ratón'. Por su parte, la denominación de este músculo con el término ratón parece ser un calco semántico tomado del francés, en donde souris 'ratón' tiene también el significado de músculo de una extremidad (s. XIII «soris de le gambe», CNRTL) y en especial la referida al cordero (1694 «muscle charnu à l'extrémité du gigot», CNRTL). En Costa Rica, también existe un corte de carne denominado posta de ratón (Quesada-Pacheco, 1991 [2007]).

La acepción 17 parece ser producto de la comparación de un criado doméstico con este animal, también doméstico.

Por otra parte, la acepción 16, gato como 'variedad de pastel', no puede ser derivada del sentido original de 'mamífero carnívoro de la familia de los Félidos'. Esto se debe simplemente a que proviene de otro étimo distinto. Esta palabra es una adopción o préstamo tomado del francés gâteau 'pastel'.

El lema gato $^{2}$ está correctamente identificado como una adopción tomada del quechua.

El lema gato $^{3}$, al ser incluido dentro de la clase de los adjetivos, aparece diferenciado de la entrada de gato $^{l}$, la cual solo incluye sustantivos. El sentido de 'que tiene ojos verdes o azules' es evidentemente una comparación metafórica con el color característico de los ojos de estos felinos. Desde un punto de vista etimológico, la distinción de este tercer lema es totalmente ociosa.

Huelga decir que el Diccionario de la Real Academia Española, en muchos casos, carece de precisión etimológica, sobre todo en cuanto a los americanismos.

Un diccionario etimológico de americanismos debería tomar muy en cuenta la homonimia y, por tanto, incluir para el vocablo de gato por lo menos los siguientes lemas:

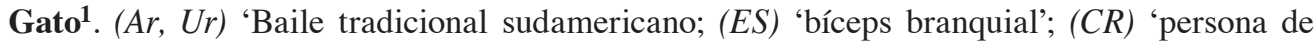
ojos verdes': del latín cattus 'gato silvestre', derivado de catta 'ídem', de origen incierto, pero seguramente de alguna lengua de la familia afroasiática (cf. árabe qitt 'ídem’). 
Gato $^{2}$. $(\mathrm{Pe})$ 'Mercado al aire libre': del quechua qhatu 'mercado; puesto de ventas; negocio', relacionado con qhatuy 'vender; comerciar'.

Gato $^{3}$. (CR) 'Variedad de repostería': del francés gâteau 'pastel', de gastel 'masa de tarta', del fránquico antiguo *wastil 'alimento', derivado de *wahs 'cera', del PG [protogermánico] *wakhsan 'ídem'.

En segundo lugar, está el caso de los diccionarios propiamente de americanismos, los cuales tampoco están exentos de imprecisiones etimológicas. Por ejemplo, el Nuevo diccionario de americanismos e indigenismos de Marcos Morínigo (1998), también ilustra las complicaciones que derivan de incluir homónimos en una misma entrada. A pesar de que este diccionario incluye etimologías para ciertas voces, especialmente para muchos indigenismos, aparecen discordancias debidas al pasar por alto la homonimia. Este autor define tres sentidos para el lema joco.

Joco, ca. (Del náhuatl xococ, agrio.) adj. Cen. y Méx. Agrio. Se dice de las frutas fermentadas. I Col. Hueco. I Cos. Agrio en general. Se dice también del sudor y del aliento humanos.

Es evidente que la segunda acepción del término difícilmente está relacionada con los otros dos significados. El hecho de asignar la misma etimología para todas las acepciones resulta claramente engañoso.

En un diccionario etimológico habría que establecer dos entradas distintas para estas acepciones.

Joco'. (CA, Me) 'Agrio; fermentado, en especial la leche'; $(C R)$ 'hediondo': del náhuatl xokok 'agrio, ácido'.

$\mathbf{J o c o}^{2}$. (Co) 'Hueco': del quechua hutk’u 'hueco, cóncavo; hueco, hoyo, agujero'.

En tercer lugar, se hallan los diccionarios de variedades regionales. Como se ha dicho, en especial, los diccionarios más modernos, al no contener referencias etimológicas, presentan en una misma entrada definiciones que son realmente incompatibles.

Por ejemplo, esto sucede con el lema china en el Nuevo diccionario de costarriqueñismos de Quesada-Pacheco, el cual corresponde a dos vocablos distintos en su origen. Sin embargo, este autor consigna las acepciones en una misma entrada.

China. f. Niñera // 2. [Bot.] Nombre de planta ornamental que da flores de diversos colores, muy común en los jardines (Impatiens wallerana).

En un diccionario etimológico, las distintas acepciones deberán aparecer en entradas distintas.

China1. 'Niñera': del quechua china 'hembra tanto animal como humana; hija; muchacha; sirvienta'.

China $^{2}$. 'Planta ornamental (Impatiens wallerana)': del nombre del país China, del portugués China (usado primero en italiano por Marco Polo), del sánscrito Cīna 'chinos', seguramente del nombre de la dinastía Qin (pronunciado “chin"), durante la cual se formó el primer imperio chino. Probablemente, esta planta fue denominada así por ser originaria de China. 
Es interesante mostrar que, por otro lado, en algunas ocasiones este autor consigna en entradas distintas, palabras que provienen del mismo étimo. Esto sucede también con otros autores.

Zorra. f. Mujer que tiene amoríos con varios hombres.

Zorra. f. (Zona Noroeste) [Ict.] Cierto pez de color cenizo, picudo.

Ambas voces presentan un origen etimológico idéntico. Si se incluyera, la entrada quedaría especificada de la siguiente manera en un diccionario etimológico:

\begin{abstract}
Zorra. 'Mujer de una moral sexual considerada muy liberal; especie de tiburón de la familia Lamnidae (Alopias vulpinus)': de zorra 'prostituta; mamífero cánido carnicero (Vulpes vulpes)', del portugués zorra 'holgazán', derivado del portugués antiguo zorrar 'arrastrar'. La denominación del cánido con esta palabra tenía carácter de vituperio. El nombre del animal acuático proviene de la abreviación de la frase pez zorra, llamado así debido a que la longitud de su cola, que es igual o superior al de resto de su cuerpo, recuerda la del zorro.
\end{abstract}

Por otro lado, es interesante señalar que, en algunos casos, la indeterminación de la homonimia llega a ser desorientadora también con los vocablos derivados. Considérese el caso del lema guapote consignado en el Diccionario de la Real Academia Española:

Guapote, ta. (Del aum. de guapo) 1. adj. coloq. Bonachón, de buen genio. II 2. coloq. De buen parecer. II 3. m. C. Rica, Guat. y Nic. Pez de agua dulce, muy carnoso, de ocho a doce pulgadas de longitud.

En realidad, la tercera acepción consignada en la entrada anterior no se deriva del español guapo, sino que proviene de una lengua indígena americana.

Guapote. (CR, Gu, $\mathrm{Ni}$ ) 'Pez de agua dulce de la familia Cichliadae (Herotilapia multiespinosa)': del náhuatl wapo-tl 'ídem', probablemente del totonaco waapa 'ídem'.

Lo mismo sucede con el lema mapachín. En el Diccionario de Americanismos de la Asociación de Academias de la Lengua Española, este vocablo aparece en una entrada distinta a la de mapache. Sin embargo, no queda claro si se trata de un derivado del lema mapache o no, al igual sucede con el término mapachito. Sin embargo, aunque tanto mapachín como mapachito comparten, evidentemente, la raíz con la voz mapache, el primero no constituye una derivación, mientras que el segundo sí. Así, estos vocablos quedarían especificados de la siguiente forma:

Mapache. (Me, Gu, Ho, ES, Ni, CR, Co, Ec) 'Mapache (Procyon lotor)': del náhuatl mapach-tli 'ídem'.

Mapachín. (Ho, Ni, Co) 'Mapache (Procyon hernandezii)': del náhuatl mapachin 'ídem'.

Mapachito. (Me:SE) 'Mapache de menor tamaño que la especie común (Procyon pygmaeus)': de mapache + -ito sufijo diminutivo, del latín -itus.

Probablemente, la forma mapachín proviene de la variedad de azteca denominada nicarao, que se habló en Honduras, Nicaragua y el norte de Costa Rica en la época de la conquista española, pues aparece reportada como regionalismo en estos tres países. 
Aunque es verdad que los diccionarios etimológicos del español general incluyen una buena cantidad de los llamados americanismos históricos, estos no toman en cuenta la mayor parte de los americanismos. Para citar también tan solo un ejemplo, del total de 505 entradas que constituyen el apartado de la letra $\mathrm{G}$ del Nuevo diccionario de americanismos $e$ indigenismos de Morínigo (1998), solo 25 de estos lemas aparecen en la letra correspondiente del Breve diccionario etimológico de la lengua castellana de Joan Coromines de 1961 [2010], la cual contiene 300 entradas.

\section{El proyecto de un Diccionario etimológico del español de Costa Rica}

El panorama anterior muestra de forma evidente que existe un campo abierto para la indagación etimológica del español en América. Como parte de este estudio, el autor se ha propuesto la tarea de elaborar un diccionario que recoja las etimologías de los vocablos regionales que, por contraste con el español general, aparecen como costarriqueñismos.

Actualmente, este trabajo se halla en proceso y forma parte de un proyecto mayor de investigación etimológica del español. En una segunda etapa, esta obra pretende abarcar el ámbito completo del español de América Central. Finalmente, en una tercera etapa, incluirá el estudio etimológico de más americanismos.

A continuación se presenta una tipología de los vocablos que han sido incluidos en los diccionarios con una marca de costarriqueñismo, de acuerdo con sus características etimológicas.

El primer tipo de voces está constituido por aquellas palabras no derivadas, las llamadas primitivas o simples y las compuestas, las cuales difieren del uso de general por presentar una acepción particular distinta, pero cuyas formas son idénticas en el español general.

Pareciera que, en muchos casos, la anotación etimológica sea innecesaria, pues, otras fuentes pueden dar perfecta cuenta de su origen. Sin embargo, no pocas veces vale la pena incluir información enciclopédica que explique el origen del significado del uso regional del término. Algunos ejemplos de esta categoría son los siguientes:

Boca. 'Bocadillo servido como acompañamiento de una bebida; alimento ligero que se toma antes de las comidas como aperitivo': aféresis de abreboca 'alimento ligero que se toma antes de las comidas como aperitivo', de abrir + boca 'abertura anterior por la que se ingieren los alimentos', del latín bucca 'boca, originalmente mejilla'.

Plátano. 'Árbol de la familia Musaceae (Musa paradisiaca, Musa sapientum); su fruto; homosexual, afeminado (término ofensivo)': del latín platanus 'árbol de familia Plantacea', del griego plátanos 'ídem', de platanistos 'nombre de una especie específica de platanácea de Asia Menor (Platanus orientalis)', de platys 'ancho, extenso', en referencia a sus hojas, del PIE *plat 'extender', de *pele 'extenso, llano, plano'. El sentido de 'homosexual' se debe al empleo de este término como un eufemismo del vocablo playo 'ídem'.

Parte. 'Multa por infracción de las normas de tránsito': abreviación de la frase parte de tránsito, de parte 'escrito generalmente breve que sirve para notificar o dar aviso', del latín pars, -tis 'porción indeterminada de un todo', del PIE *per 'asignar, repartir, distribuir'.

Buzo. 'Ropa deportiva que consta de un pantalón amplio y una sudadera hechos del mismo material y color; persona que hurga en los basureros para reciclarlos': de buzo 'el que trabaja sumergido en el agua', del portugués búzio 'ídem', originalmente 'caracol que vive debajo del agua', del latín bucina 'cuerno de boyero'. El primer sentido proviene de la abreviación de la frase metafórica traje de buzo. 
Pargo. 'variedad de peces de la familia Lutjanidae (Lutjanus vivanus); vagabundo, holgazán': de pargo, variante de pagro 'pez de la familia Sparidae (Pagrus pagrus)', del latín pagrus 'ídem'. Los peces de la familia Lutjanidae viven en un mar de clima subtropical asociados a los arrecifes de coral. Por su movimiento sosegado en aguas tranquilas parecen tener una lentitud semejante a la atribuida a un holgazán.

Tiricia 'pereza, desidia, desgano': de tiricia o tericia, formas arcaicas y populares derivadas de ictericia 'enfermedad producida por acumulación de pigmentos biliares en la sangre, cuyo síntoma más visible es la amarillez de la piel', del latín medieval icteritia 'ídem', derivado del adjetivo ictericus 'quien padece esta enfermedad', del griego ikterikós 'ídem', derivado del sustantivo íkteros 'ictericia'. Se supone que la raíz íkt(er) se refiere al 'color amarillo' en griego, porque aparece en ciertos vocablos de animales que presentan esa coloración característica (iktinós 'marta', íktis 'milano'). El significado de 'pereza, desidia, desgano' proviene de la percepción tradicional de que las enfermedades hepáticas tienen como consecuencia un desgano vital.

El segundo tipo de voces agrupa a los vocablos cuyas formas no se consignan en el español general. Se trata sobre todo de los préstamos de otras lenguas. Desentrañar el origen etimológico de estas adopciones constituye, quizá, el reto mayor de esta empresa. Algunos ejemplos de estos casos son los siguientes:

Cacharpa. 'Automóvil que no funciona bien o está viejo': del quechua kacharpa 'bártulos, trebejos, utensilios y ropa de poco valor y, por extensión, cosas viejas', derivado de kacharpariy 'despedir; acompañar por cortesía al que sale de viaje', derivado de kachay 'remitir, enviar'. El sentido de 'bártulos, trebejos' proviene de la idea de que el equipaje contiene los enseres de un viajero.

Chante. 'Casa, hogar, local, lugar': del inglés shanty 'casucha, choza, tugurio', del francés canadiense chantier 'barraca de leñador', en francés estándar 'barraca de madera, puerto', del francés antiguo cantier 'soporte, plataforma, astillero', del latín cantherius 'viga, potro para sujetar a los caballos', originalmente 'caballo castrado, rocín, jumento, caballo de carga', del griego kanthélios 'asno'.

Chinchorro. 'Casucha, tugurio': del euskera txintxor 'grava, cascote de piedra, escombros de una edificación derribada o arruinada'.

Estrilar. 'Reclamar, renegar': del italiano estrilare 'chillar, gritar', derivado de strillo 'grito fuerte y agudo', de la forma sincopada *strid'lo, que proviene del diminutivo stridulo 'ídem', derivado del verbo stridere 'gritar aguda y ásperamente, en especial como lo hacen los animales', del latín stridere 'ídem'.

Ful. 'Lleno': del inglés full ‘ídem’, del PG *fullaz 'ídem', del PIE *pel 'llenar'.

Jamar. 'comer': del caló gitano jamar 'ídem', del romaní (familia indoeuropea, rama indoaria) han- 'ídem'.

El tercer tipo de vocablos está constituido por las palabras derivadas, que toman como base un término del español general u otro costarriqueñismo. Dos ejemplos de esta clase son los siguientes: 
Chichota. 'Bulto que se forma en la cabeza a causa de un golpe': derivado de la forma regresiva *chicha de chichón 'ídem', del latín abscessio, -onis 'ídem', derivado de abscessus 'tumor' (literalmente, 'separación'), derivado de abascedere 'retirarse, alejarse', de abs- 'desde'(del PIE *apo 'desde lejos') + cedere 'moverse' (del PIE *ked 'ídem') + -ota terminación de sustantivos con valor aumentativo.

Desbarrancarse. 'Caer en un despeñadero; contraer matrimonio': verbo derivado de desprefijo que indica la compleción de un evento, el latín dis- 'ídem' + barranco 'precipicio por donde puede despeñarse algo', origninalmente 'torrente profundo', de origen ibérico prerromano.

Desmoletar. 'Quitar las muelas o los dientes': verbo derivado de des- prefijo de negación, del latín dis- 'ídem' + moleta 'muela pequeña', de muela 'cada uno de los dientes posteriores a los caninos', del latín mola 'piedra de moler', del PIE *mel 'frotar, moler' + -eta terminación de sustantivos con valor diminutivo, femenino de - ete 'ídem', del francés antiguo - et 'ídem', del latín -itus 'ídem'.

Helazón. 'Frío intenso': nombre derivado de helar, del latín gelare 'helarse, congelarse', de gelu 'hielo' + -ón terminación de sustantivos que indica el efecto o estado de un evento, del latín -ionem 'ídem'.

Fulear. 'Llenar por completo de combustible un automóvil': verbo derivado de $f u l+-e$ sufijo de significado frecuentativo.

El cuarto tipo de voces corresponde a los calcos semánticos tomados de otras lenguas. Estos son de dos clases: extensiones de significado de una lexía ya existente por influencia de una lengua extranjera y traducciones literales de frases o lexemas pluriverbales de otra lengua. Algunos ejemplos de este tipo son los siguientes:

Aplicación. 'Solicitud hecha por escrito; formulario para la solicitud': calco del inglés application 'solicitud' (1851).

Celular. 'Teléfono móvil': Abreviación de la frase teléfono celular 'ídem', calco del inglés cellular phone 'literalmente, teléfono celular' (actualmente cell phone) (1977). La denominación de celular se debe a que los sistemas de servicio telefónico móvil utilizan una red de transmisores para una área de cobertura de unos cuantos kilómetros cuadrados llamado técnicamente, en los Estados Unidos, cellular network 'red de celdas, red celular'.

Concreto. 'Mezcla de piedras menudas, cemento y arena, hormigón': calco del inglés concrete ‘ídem' (1834).

Parlante. 'Aparato electroacústico que sirve para amplificar el sonido': Abreviación de la frase alto parlante 'ídem', calco del inglés loudspeaker 'literalmente, alto parlante' (1884).

Patear el balde. 'Morir': calco del inglés kick the bucket 'literalmente, patear el balde: morir' (1785). El sentido de esta frase proviene de la confusión de la palabra bucket 'balde' (del anglonormando buquet 'tina, cuba', del inglés antiguo buc 'barriga; cántaro'), con la voz original bucket ${ }^{2}$ 'balanza' (del francés antiguo buquet 'viga o yugo del cual se colgaban animales sacrificados en las carnicerías') reforzada por la idea del suicidio por ahorcamiento. 
Los calcos que aparecen consignados como costarriqueñismos en los diccionarios consultados son muy escasos.

Por otro lado, el análisis de las entradas correspondientes a las letras F, L, Z, tomadas como una muestra aleatoria, indica que la mayor parte de los lemas corresponden al primer tipo de relación etimológica: las extensiones de significado de un término que ya existe en el español general. La proporción de este tipo corresponde al 48,3\% del total.

El segundo tipo de relación etimológica: las palabras derivadas constituyen el $42,8 \%$ del total de todos los casos.

Finalmente, las voces que no aparecen consignadas en el español más general corresponden al $8,9 \%$ del total de la muestra. Este tipo de palabras está conformado por préstamos de diversas lenguas.

La mayor parte de estos vocablos son anglicismos y nahuatlismos. Sin embargo, hay voces de muy diversos orígenes. A continuación se muestran algunos ejemplos ilustrativos.

Inglés:

Mufla. 'Tubo de escape de los automóviles': del inglés muffler 'silenciador de automóvil', derivado de muffle 'cubrir o envolver algo para protegerlo', del francés antiguo moufle 'mitón, tipo de guante que cubre hasta el nacimiento de los dedos', del bajo latín muffula 'ídem', probablemente del fránquico antiguo *muff 'envoltura' + vël 'piel de animal'.

Náhuatl:

Tanate. 'Paquete de cosas; montón; lío, embrollo', del náhuatl tana-tl 'zurrón, espuerta hecha de tejidos de palma'.

Quechua:

Napa. 'Algo que se da por añadidura por una compra': del quechua yapa 'aumento, incremento, añadidura'.

Huetar:

Purruja. 'Insecto díptero de la familia Psychodidae (Phebotomus papatasi)': del huetar (familia chibcha) purrux 'ídem', del PC [protochibcha] *burru 'ídem' + - $a$ marcador de género.

Chorotega:

Nimbuera. 'Vasija de gran tamaño usada para almacenar agua': del chorotega (familia otomangue) nimpu 'agua, lluvia' + -era terminación que indica pertenencia o relación, del latín -aria 'ídem'.

Romaní:

Acoi. 'Aquî́: del caló gitano acoi 'aquí, acá', del romaní (familia indoeuropea, rama indoaria) ákaj 'aquí', de aká 'este'.

Francés:

Fuete. 'Látigo': del francés fouet 'ídem' (literalmente, 'hayita', es decir, 'varilla de haya'), diminutivo del francés antiguo fou 'haya', del latín fagus 'ídem', del PIE [protoindoeuropeo] *bhagos 'ídem'. 
Alemán:

Kinder. 'Escuela de párvulos': abreviación de kindergarten 'ídem', del alemán Kindergarten 'ídem', literalmente ‘jardín de niños’, de Kind 'niño' + - er sufijo plural (del PG [protogermánico] *kinthan 'ídem', del PIE [protoindoeuropeo] *géntom 'ídem') + Garten 'jardín' (del alto alemán antiguo garto 'ídem', del PG *garda 'recinto, patio, jardín', del PIE *gharto- 'ídem', derivado de *gher 'agarrar, encerrar, cercar').

Italiano:

Fututo. 'Difícil, infortunado; atolondrado; ebrio': de fotuto 'deteriorado, dañado, perjudicado, enfermo', del italiano fottuto 'jodido, fastidiado', derivado de fottere 'joder, practicar el coito; perjudicar; fastidiar', del latín futuere 'practicar el coito', del PIE [protoindoeuropeo] *bhaut 'golpear, pegar'.

Portugués:

Garúa. 'Llovizna': de garuja 'ídem', del portugués dialectal caruja 'niebla', del latín vulgar *calugo, -inis, en latín clásico caligo, -inis 'niebla, humo, tinieblas'.

Inglés criollo limonense:

Patí. 'Empanada picante rellena de carne': del inglés criollo limonense páti 'ídem', del inglés patty 'pastelillo, empanada'.

Kikongo:

Tufí. ‘Trozo de excremento sólido’: del kikongo (familia níger-congo) tufi 'excrementos'.

Esta lista de adopciones de otras lenguas es amplia y diversa. Los avatares de los medios por los cuales estas fueron incorporadas en el habla costarricense son, sin duda, tan fascinantes como intrincados. Su esclarecimiento develará las complejas relaciones y los múltiples intercambios sociales que han existido entre los hablantes en el ámbito del mundo hispanoamericano.

\section{Costarriqueñismos, centroamericanismos, americanismos}

El estudio etimológico del español hablado en Costa Rica, como era de esperarse, ha llevado a la corroboración de que una inmensa cantidad de vocablos, que contienen la marcación de un uso geográfico propio de este país, también son utilizados en otros países de América Central. A pesar de que apenas muy recientemente se ha llamado la atención al reconocimiento de un español centroamericano como una zona dialectal hispanoamericana (cf. Quesada-Pacheco, 2000, pp. 191-193), no queda duda de que las naciones centroamericanas comparten un acervo léxico distintivo.

Un repaso somero de algunas obras lexicográficas que contienen americanismos ponen en evidencia este aserto. Del Diccionario de americanismos de la Asociación de Academias de la Lengua Española (2010), puede considerarse, en primer lugar, el vocablo chibola como un ejemplo de ello:

chibola. (Del maya tzibol, bulto, pelota)

I. 1. f. $\mathrm{Gu}, \mathrm{Ho}, \mathrm{ES}, \mathrm{Ni}, \mathrm{CR}, \mathrm{Pa}, \mathrm{Co}: \mathrm{N}$. Abultamiento redondeado que se forma en una parte del cuerpo, especialmente en la cabeza, a causa de un golpe. pop. (chibolo).

2. $\mathrm{Gu}, \mathrm{Ho}$, ES. Pelota, bola, o canica que se utiliza en ciertos juegos y deportes. pop. 
3. $N i, C R$. Cuerpo esférico pequeño.

4. Ho. Bola metálica que tienen ciertas cerraduras de puertas. pop.

II. 1. f. $G u, H o, E S$. Persona muy gorda. pop.

III. 1. f. pl. Ho. Testículos. pop.

2. Ho. Ojos grandes y saltones de persona. pop.

IV. 1. f. ES, Ni. obsol. Botella de gaseosa. pop.

Aunque no sea tan evidente, todas las acepciones (de la I a la IV), con sus significados secundarios, parecen estar relacionadas. Así, la acepción IV se explicaría porque, a principios del siglo XX, las botellas de refrescos llevarían como cierre una pequeña esfera de vidrio. ${ }^{2} \mathrm{Se}$ trata, pues, de un caso de metonimia. Las acepciones II y III corresponden, claramente, a casos de metáforas humorísticas. La acepción I parece contener el significado primario de la entrada. Es muy probable, que el significado 1 de esta acepción sea el original.

En cuanto al origen del vocablo chibola, el Diccionario de americanismos ha optado por admitir la etimología propuesta por Santamaría (1942, tomo 1, p. 481), quien le atribuye una procedencia maya: de tzibol. Este autor constata que, en el español de Yucatán, ("la región peninsular oriental"), México, existe la forma chibol 'protuberancia, chichón, bodoque', la cual provendría directamente del vocablo maya y habría dado origen a los términos chibola y chibolo.

Sin embargo, esta etimología presenta varios problemas. En primer lugar, ya sería inusual que un mayismo, supuestamente usado en Yucatán, se extendiera por toda América Central. Pero, todavía sería más extraño que un mayismo llegara hasta Colombia, Ecuador y Perú, como sucede según el Diccionario de la Real Academia y, sin embargo, fuera totalmente desconocido en México.

En segundo lugar, este supuesto mayismo no aparece identificado como tal ni siquiera en el español de la Península de Yucatán. Por ejemplo, Pérez-Aguilar (2001), en su estudio "Indigenismos en el español hablado en Chetumal", que es una población mexicana de origen maya, capital del Estado de Quintana Roo, incluye 80 mayismos y entre ellos no menciona este vocablo. Por otra parte, Alcalá-Philips (2009), en su estudio "Mayismos en el léxico del español de Cancún, Quintana Roo, México", quien elabora una lista de 150 posibles mayismos usados en el español de esa ciudad, tampoco registra el término tzibol.

Finalmente, tzibol (o una variante ortográfica menos tradicional tsibol) ni siquiera aparece registrada en diccionarios de maya yucateco, como el Gómez-Navarrete (2009) por ejemplo, lo cual resulta muy sospechoso.

Así las cosas, lo más probable es que el término tzibol, aducido por Santamaría como el étimo original de chibolo, sea más bien un préstamo en maya tomado del español de la región, chibol, que el mismo Santamaría ha indicado de uso en Yucatán.

Más bien, el autor del presente trabajo comparte el criterio de la etimología propuesta por Coromines y Pascual (1980-1991), quienes derivan chibolo de "un cruce de chichón con bolo, bola" [vid. lema CHICHÓN]. Así, pues, en el diccionario etimológico, la entrada aparecería de la siguiente forma:

Chibola. (CA, $C o: N, E c, P e)$ 'Abultamiento del cuerpo; pelota, bola, canica; ( $E S, N i)$ botella': cruce entre chichón 'bulto en la cabeza' y bola 'cuerpo esférico'.

Otros ejemplos de centroamericanismos son los vocablos tuanis, pelis y peli, que aparecen también en el Diccionario de americanismos de la Asociación de Academias de la Lengua (2010), para los cuales no se ofrece ninguna etimología. 
tuanis.

I. 1. adj. Gu, Ho, ES, Ni, CR. Muy bueno, excelente. pop.

2. Ho, ES, Ni. Referido a una cosa, bonita.

3. Ho, ES, Ni. juv. Referido a una cosa, que está de moda.

4. Ho. Referido a una cosa, muy grande.

II. 1. adv. Ho, ES, Ni. Bien.

pelis.

I. 1. adj/sust. Ho. ES. Referido a persona, atenta o pendiente de algo o alguien.

2. Ho, ES. Referido a un concierto o actuación, bueno, excelente.

3. Ho. Referido a persona, lista.

4. Ho. ácido, experto en algo.

II. 1. adj. Ho, CR, Referido a una situación, problema o asunto. Difícil de solucionar o de comprender.

III. 1. m. pl. Ho. juv. Pelos.

IV. 1. CR. p.u. peli. pop.

peli.

I. 1. adj. Ho, ES. Referido a cosa, que es mala o fea (pelis).

En América Central, los vocablos tuani, tuanis, peli y pelis son usados en un ámbito jergal exclusivamente. Provienen de la aplicación de un código secreto conocido como malespín, el cual habría sido inventado con fines militares por un general salvadoreño llamado Francisco Malespín en el siglo XIX (Valle, 1948). Este código consiste en intercambiar varias letras de las palabras: la $a$ por una $e$ y viceversa, la $i$ por una $o$ y viceversa, la $b$ por una $t$, la $c$ por una $s$, la $f$ por un $g$ o $j$ y la $m$ por una $p$.

Así, entonces, bueno da como resultado tuani, mientras que malo origina peli. En Costa Rica, por lo menos, la adición de la consonante $s$ al final de estas palabras parece deberse a un rasgo estilístico propio del habla hampesca cuando la palabra termina precisamente con la vocal $i$. Por ello, se registran la variantes acoi y acois 'aquí' (del caló gitano acoi 'aquí') en el español de Costa Rica.

De esta forma, todas las acepciones y significados del vocablo tuanis 'muy bueno, excelente, bonito, muy grande, bien' pueden ser fácilmente derivados del sentido del étimo original 'bueno'.

En relación con los otros dos términos, en peli se conserva la acepción original del étimo, mientras que en pelis la acepción I presenta significados más bien contrarios al sentido de étimo original. Esto sucedería por la asimilación total de un uso irónico del sentido de 'malo' por 'bueno'. Las acepciones II y IV recogen, nuevamente, el sentido original del vocablo. Finalmente, la acepción III 'pelos' no tiene relación etimológica con las demás ya mencionadas, pues proviene evidentemente de pelo 'vello; cabello'.

Finalmente, habría que agregar que estos vocablos se utilizan también en Guatemala, pero no en Panamá. Esto se debe a que estas se empezaron en el contexto de las guerras civiles centroamericanas, en el siglo XIX, cuando la actual Panamá todavía formaba parte de Colombia.

En el diccionario etimológico habría que consignar las entradas de la siguiente forma:

tuanis. (Gu, Ho, ES, Ni, CR) 'Bueno; muy bueno; grande': de tuani 'bueno', en malespín: $\mathrm{b}=$ $\mathrm{t}, \mathrm{a}=\mathrm{e}, \mathrm{o}=\mathrm{i}$. La consonante $s$ final es un rasgo estilístico del habla hampesca.

pelis' ${ }^{1}$ ( $\left.G u, H o, E S, N i, C R\right)$ 'Malo; difícil; bueno; listo': de peli. La consonante $s$ final es un rasgo estilístico del habla hampesca. 
pelis ${ }^{2}$. (Ho) 'Pelos': plural de pelo 'vello; cabello', del latín pilus 'vello'.

peli. ( $G u, H o, E S, N i, C R$ ) 'Malo; difícil; bueno; listo': de peli 'malo', en malespín: $\mathrm{m}$ = p, a $=\mathrm{e}, \mathrm{o}=\mathrm{i}$.

Por otra parte, como también ha quedado en evidencia, muchísimos de los vocablos que pueden ser considerados centroamericanismos son utilizados en otros países americanos, desde México hasta Chile y Argentina. Por tanto, se trata de auténticos americanismos. Por ello, un proyecto de investigación etimológica del español de América Central terminará siendo también de relavancia para el estudio del español de toda Hispanoamérica.

El análisis del caso del vocablo chicha permite ilustrar la pertinencia de la indagación etimológica en el estudio de los americanismos. El uso de esta palabra está extendido por toda hispanoamérica. Esto aparece corroborado en la entrada correspondiente que aparece en el Diccionario de americanismos de la Asociación de Academias de la Lengua Española.

\section{chicha.}

I. 1. f. $M x, G u, H o, E S, N i, C R, C o, V e, E c, P e, B o, C h, A r$. Bebida alcohólica que resulta de la fermentación de ciertos cereales como el maíz, el arroz o la avena, de tubércolos como la yuca, o de frutos como la piña, en agua azucarada. [...]

3. $C u, P y$. Bebida refrescante que se obtiene con azúcar y cáscaras frescas de piña [...]

6. $P a$. Refresco hecho con frutas y azúcar.

II. f. Pe. Manifestación cultural [...] desarrollada por inmigrantes andinos en ciudades grandes como Lima.

III. 1. f. Pe. Actividad informal, de mal gusto y de baja calidad.

IV. 1. f. $P e$. Género musical que mezcla diferentes ritmos.

V. 1. f. $\mathrm{Cu}$. Cigarro de marihuana. drog.

VI. 1. f. $N i$, $C R$. Cólera, enojo. pop.

VII. 1. Ni. Seno de mujer o teta de animal.

Este diccionario no proporciona ninguna etimología para este término. En el Nuevo diccionario de americanismos e indigenismos de Morínigo sí aparece una referencia etimológica.

\section{CHICHA}

(Parece ser voz de los indios cunas de Panamá)

Lo mismo sucede en el Diccionario de la Real Academia Española:

chicha $^{2}$

(De la voz aborigen de Panamá chichab, maíz)

Por su parte, Coromines y Pascual (1980-1991) establecen lo siguiente:

CHICHA I. 'bebida alcohólica usada en América y resultante de la fermentación del maíz, y de otros granos y frutos, en agua azucarada.', parece ser voz de los indios cunas de Panamá.

Estos dos últimos autores, luego de mencionar brevemente dos propuestas sobre el origen de esta palabra, que lo asignan a los 'arauacos antillanos' (Zárate y Acosta) y al náhuatl (Lenz), indican que Oviedo atribuye categóricamente el vocablo a la lengua de Cueva, es decir, a los Cunas, zona de Panamá y agregan lo siguiente:

Wafer, viajero que visitó el Istmo a finales del siglo XVII, cuando todavía estaba el idioma indígena, lo confirma, advirtiendo que es abreviación de chichah co-pah, donde chichah significa 'maíz' y co-pah 'bebida'. [Coromines y Pascual, 1980-1991, vid. entrada de chicha I] 
De acuerdo con lo anterior, parece que Morínigo se basa en Coromines y Pascual para afirmar que la palabra chicha sea de origen cuna. El cuna es una lengua indígena de estirpe chibchense, hablada en el Oriente atlántico de Panamá. Sin embargo, al parecer, los indígenas cuna no llegaron a los territorios ocupados por los cueva sino hasta el mismo siglo XVII (Martínez-Mauri, 2011, p. 34).

Fernández de Oviedo menciona, por primera vez, el vocablo chicha en su obra Sumario de la historia natural de las Indias publicado 1526, el cual relata especialmente su estancia en Tierra Firme, denominación colonial de parte de la actual Panamá y parte de Colombia, en 1514:

\footnotetext{
[...] i en este medio tiempo andan otras Personas detràs de ellos, dandoles á beber vn Vino, que ellos llaman Chicha, de el qual adelante serà hecha mencion, i beben tanto, que muchas veces se tornan tan beodos, que quedan sin sentido. (Fernández de Oviedo, Capítulo X De los Indios de Tirrra-firme y de sus costumbres y ritos y ceremonias, folio 17)
}

Es importante señalar que Fernández de Oviedo está describiendo un tipo de baile (llamado Areyto) de los indios cueva o cueba, que habitaban el Darién en el oriente de Panamá, el cual formaba parte de la juridicción colonial denominada de Castilla de Oro, la cual también incluía gran parte de la actual Colombia.

\begin{abstract}
Pero vna gran Provincia de Castilla de Oro, que se llama Cueva, hablan, i tienen mejor lengua mucho, que en otras partes, i en aquella es donde los Christianos estàn enseñoreados: i toda la dicha Lengua de Cueva, ò la maior parte, la tienen sojuzgada. (Fernández de Oviedo, Capítulo X De los Indios de Tierra-firme y de sus costumbres y ritos y ceremonias, folios 12-13)
\end{abstract}

La atribución de este vocablo "a la lengua de Cueva" por parte de Coromines y Pascual se debe probablemente a este relato. Sin embargo, estos autores cometen el error de identificar la llamada lengua cueva con el cuna. Incurren en esta imprecisión, probablemente, a causa de que Loukotka (1968) y Greenberg (1987) identifican al cueva como una lengua chibcha, especialmente afín al cuna, y porque algunos autores han planteado la hipótesis de que los cunas son los descendientes modernos de los cuevas (cf. Martínez-Mauri, 2011, pp. 31 y ss).

Sin embargo, tanto Loewen (1963) como Constenla y Margery (1991) aportan indicios lingüísticos que permiten, con bastante seguridad, establecer la filiación del idioma cueva con la familia lingüística chocó. ${ }^{3}$

De este modo, habría que descartar como incorrecta la precisión etimológica de Morínigo, quien, como se ha dicho, identifica el vocablo chicha como "voz de los indios cuna de Panamá", al igual que la equiparación que hacen Coromines y Pascual de los indios cueva con los cuna.

Por otro lado, como se ha dicho, Coromines y Pascual citan a Lionel Wafer, un cirujano británico que vivió durante cuatro meses con indígenas cuna en Panamá en 1681. En su relato del viaje, Wafer recoge algunos vocablos, entre los cuales se encuentra la palabra chicha. El texto original en donde aparece la palabra es el siguiente:

I took to no Care to retain any of the Indian Language; but some few Words tha I still remember, I have here put as a Specimen.

Tautah, Father.

Naunah, Mother.

Poonah, Woman. [...]

Nee, The Moon. [...]

Doolah, Water.

Pa poonah cetha Coupah? Woman have you got the Hammock?

Doolah Copah? Will you drink Water?

Chicha-Copah, Maiz-Drink. (Wafer, 1695 [1704], p. 150) 
En primer lugar, hay que señalar que, ya para la época en que Wafer visita el istmo panameño, el último cuarto del siglo XVII, los indígenas cueva habían desparecido por completo, desde mediados del siglo XVI (Romoli, 1987, pp. 49-50). En segundo lugar, las palabras recogidas por Wafer corroboran, indudablemente, que los términos recogidos corresponden a la lengua cuna. Así, por ejemplo, los vocablos para 'mujer', poonah, y 'madre', naunah, se corresponden con los términos / puna / y / nana / del cuna. Lo mismo sucede con las palabras nee 'luna' y copah 'beber', que son / nii / y / kop- / en cuna. Fernández de Oviedo recoge, en cueva, la palabra ira con el significado de 'mujer'. Este es un indicio muy fuerte que hace descartar toda posibilidad de que las palabras recogidas por Wafer fueran de la lengua cueva.

En este mismo relato, Wafer cita, por primera vez, la palabra chicha en el siguiente texto:

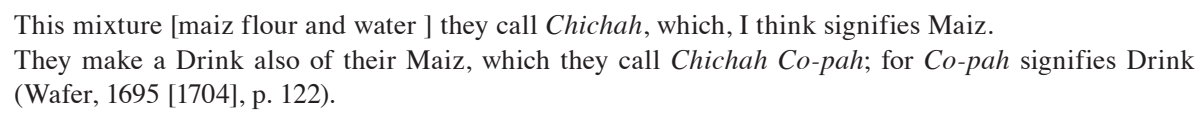

Es importante señalar que Wafer manifiesta explícitamente que el significado asignado a Chichah como 'maíz' es una suposición de su parte. Quizá por ello y con razón, ni Coromines y Pascual (1980-1991) ni los autores del Diccionario de la Real Academia Española se arriesgan a proponer un significado al étimo de chicha que citan.

De hecho, la palabra para 'maíz' en cuna es $o b a$, la cual, posiblemente, está relacionada con el étimo *ebe 'maíz' del protochibcha. ${ }^{4}$ Es evidente que el término identificado por Wafer no podría significar 'maíz'.

Por este motivo, la palabra chicha recogida por Wafer, muy probablemente, sería un hispanismo usado por estos indígenas y la frase recogida por Wafer chicha-copah o chichah co-pah significaría más bien algo así como ‘jbeba chicha!’.

En cuanto a la forma chichab, aducida en el Diccionario de la Real Academia Española como el étimo de chicha, con una consonante $b$ al final en lugar que de una $h$, como aparece claramente en Wafer (1695 [1704]), se debe indicar que se trata de una equivocación de lectura. Los autores de este diccionario confundieron la letra $h$ del texto con la letra $b$. Esto ocurrió así, con toda seguridad, porque habrían utilizado como fuente documental la edición de la obra de Wafer de 1729 (vid. bibliografía). En este texto, el tipo de letra usado para la letra $h$, al ir en cursiva, por tratarse de vocablos citados, presenta el trazo final de la derecha muy hacia adentro, lo cual da la impresión de que se trata de la letra $b$. Por supuesto, se trata de un error minúsculo. Sin embargo, constituye un desacierto etimológico patente.

Finalmente, la misma escritura de la palabra chichah con una consonante $h$ al final, que reporta Wafer en su relato, puede ser explicada con facilidad. Se trata de un recurso ortográfico que este autor utiliza, de manera sistemática, para representar la vocal baja central / a / que existe en cuna, ${ }^{5}$ cuando esta se halla en posición final de palabra.

Por ello, Wafer escribe Chichah Co-pah, cuando escribe estas como palabras separadas, al igual que Naunah o poonah, por ejemplo. Sin embargo, anota Chicha-Copah, uniendo con un guion ambos términos como si fuera uno solo. Es probable que Wafer utilizara este recurso ortográfico para evitar que sus lectores anglohablantes interpretaran la vocal $a$ final de palabra como una "schwa", una vocal media central, como sucedería normalmente en inglés.

Entonces, en un diccionario etimológico, las entradas correspondientes al vocablo chicha serían las siguientes: 
chicha' ( $(\mathrm{Me}, \mathrm{Gu}, \mathrm{Ho}, \mathrm{ES}, \mathrm{Ni}, \mathrm{CR}, \mathrm{Pa}, \mathrm{Cu}, \mathrm{Co}, \mathrm{Ve}, \mathrm{Ec}, \mathrm{Pe}, \mathrm{Bo}, \mathrm{Py}, \mathrm{Ch}, \mathrm{Ar}$ ) 'Bebida, fermentada o no, hecha de maíz o de otros ingredientes': del cueva (familia chocó) chicha 'ídem'.

chicha $^{2}$. (Pe) 'Género musical; actividad informal de baja calidad y mal gusto': aféresis de chichera 'vendedora de chicha'. "La chichera" fue un tema musical compuesto por Carlos Baquerizo Castro, el cual llevó a la popularidad el género musical chicha. Según él mismo, puso el nombre al tema musical en honor a una joven chichera de su provincia natal.

chicha $^{3}$. $(\mathrm{Cu})$ 'Cigarro de marihuana': aféresis de chicharra 'colilla del cigarro de marihuana'.

chicharra. 'Cigarra; instrumento musical cilíndrico; colilla del cigarro de marihuana': de cigarra 'insecto de la familia Cicadidae, que produce un ruido estridente'.

chicha ${ }^{4}$. (Ni) ‘Seno, teta': de la raíz de chiche ‘ídem’ + - a marcador de género femenino.

chiche. (Me, Gu, Ho, ES, Ni) 'Seno, teta': del náhuatl (familia uto-azteca) chichi 'mama, teta', de chichi-a 'chupar', probablemente de origen onomatopéyico.

En Costa Rica, la acepción de la palabra chicha como 'cólera, enojo', posiblemente, se deriva de la frase estar de chicha 'estar enojado', la cual metafóricamente significaría 'estar en un estado de efervescencia', como sucede con la fermentación de la chicha. Este sentido aparece también atestiguado, en el español ecuatoriano, con una frase semejante: estar con todita la chicha ' estar con ira' (Cordero-Palacios, 1957, p. 93). ${ }^{6}$ Por lo tanto, la acepción VI del vocablo chicha del Diccionario de Americanismos se derivaría del significado primario del término, es decir, corresponde a la entrada de chicha1.

\section{Conclusiones}

La indagación de las etimologías del español americano aparece muy prometedora y fructífera, a pesar del desinterés que ha habido por su estudio y de las evidentes dificultades que acarrea su investigación.

El tratamiento de las etimologías de los vocablos del español americano en los distintos diccionarios analizados, incluidos especialmente el Diccionario de la Real Academia Española y el Diccionario de Americanismos de la Asociación de Academias de la Lengua, ha mostrado una cierta falta de rigurosidad. Probablemente, esto se debe, en parte, a que estos diccionarios contienen una inmensa cantidad de lemas. Por ello, se consideraría recomendable que la investigación etimológica fuera realizada de manera selectiva. En este sentido apunta el proyecto propuesto por el autor de este trabajo: elaborar primero un diccionario etimológico del español de Costa Rica, luego uno de América Central y, finalmente, aunar esfuerzos para conformar un gran diccionario etimológico del español americano.

\section{Notas}

1. A pesar de que estos diccionarios no contienen indagaciones etimológicas, algunos de ellos sí indican la procedencia de algunos vocablos, aunque sea de manera meramente especulativa. Así sucede en el diccionario de Pichardo, quien, para ciertas palabras hace de la indicación de que se trata de una voz indígena americana: (vz. ind.).

2. Gagini (1919, p. 110) anota: "En toda C.A. [chibola] significa bolita y por eso en El Salvador llaman chibolas a las botellas de refrescos, tapadas con unas esferillas de vidrio".

3. La familia chochó incluye, por lo menos, dos lenguas más: el waunana (o huaunana) y el emberá (con cuatro variedades dialectales: el saija, el chamí, el catío y el sambú) (Constenla y Margery, 1991). 
4. La forma *ebe 'maíz' de esta protolengua está atestiguada en varias lenguas chibchas: / ëb / en térraba, / aba / en muisca, / éba / en tunebo y / ebi / en tunebo (Constenla, 2008).

5. Cf. Price (2005, p. 80).

6. También se utiliza en Costa Rica la frase estar con chicha, con el mismo sentido.

\section{Bibliografía}

Agüero, A. (1996). Diccionario de costarriqueñismos. San José: Asamblea Legislativa.

Alcalá-Philips, G. (2009). Mayismos en el léxico del español de Cancún, Quintana Roo, México. (Tesis de Maestría). Brigham Young University.

Alcedo, A. de. (1786-1789). Diccionario histórico geográfico de las Indias Occidentales ó América. Madrid: Imprenta de Manuel González.

Aleza-Izquierdo, M. (2000). Nuevos enfoques metodológicos en la práctica lexicográfica hispanoamericana diferencial actual (sobre algunos diccionarios de los 90). Por M. Aleza-Izquierdo \& Á. López-García (Eds.) Estudios de filología, historia y cultura hispánicas. (27-48). Valencia: Universitat de València.

Asociación de Academias de la Lengua Española. (2010). Diccionario de americanismos. Lima: Santillana.

Ayala, M.J. de. (1995 [1750-1777]). Diccionario de voces americanas. [Edición de M.Á. Quesada Pacheco]. Madrid: Arco Libros.

Batres-Jáuregui, A. (1896). Vicios del lenguaje y provincialismos de Guatemala. Guatemala: Tipografía Nacional.

Constenla, A. (2008). Estado actual de la subclasificación de las lenguas chibchenses y de la reconstrucción fonológica y gramatical del protochibchense. Estudios de Lingüística Chibcha. 27, 117-135.

Constenla, A. y Margery, E. (1991). Elementos de fonología comparada chocó. Revista de Filología y Lingüística. 17 (1-2), 137-191.

Cordero-Palacios, A. (1957). Léxico de vulgarismos azuayos. Azuay: Casa de la Cultura Ecuatoriana.

Coromines, J. (2010 [1961]). Breve diccionario etimológico de la lengua castellana. Madrid: Gredos.

Coromines, J. y Pascual J.A. (2012 [1980-1991]). Diccionario crítico etimológico castellano e hispánico. [Versión electrónica]. Madrid: Gredos.

Covarrubias, S. de. (1998 [1611]). Tesoro de la lengua castellana. Barcelona: Editorial Alta Fulla.

Fajardo-Aguirre, A. (2010). "La lexicografía del español de América”. Por M. Aleza-Izquierdo \& J.M. Enguita-Utrilla (Coord.). La lengua española en América: Normas y usos actuales. [Versión digital]. (317-353). http://www.uv.es/aleza [Consulta: 25 de noviembre de 2014].

Fernández de Oviedo, G. (1749 [1526]). Sumario de la historia natural de las Indias. Por A. González-Barcia. Historiadores primitivos de las Indias Occidentales, que juntò, traduxo en parte, y sacò a la luz, ilustrados con eruditas notas, y copiosos indices. Tomo III, Madrid: [s.n.]. 
Furt, J.M. (1927). Coreografía gauchesca: Apuntes para su estudio. Buenos Aires: Coni.

Gagini, C. (1893). Diccionario de barbarismos y provincialismos. San José: Tipografía Nacional.

Gagini, C. (2010 [1818]). Diccionario de costarriqueñismos. San José: Editorial Costa Rica.

Gelabert, P.J. (1984 [1853]). Ensayo de un diccionario aragonés-castellano. Madrid: Ediciones El Museo Universal.

Gómez-Navarrete, J.A. (2009). Diccionario introductorio español-maya/maya-español. Chetumal: Universidad de Quintana Roo.

González-Barcia, A. (1749). Historiadores primitivos de las Indias Occidentales, que juntò, traduxo en parte, y sacò a la luz, ilustrados con eruditas notas, y copiosos indices. Tomo III, Madrid.

Haensch, G. (1999-2000). La lexicografía del español de América y un nuevo diccionario de americanismos. Boletín de Lexicografía. 6, 179-208.

Loewen, J.A. (1963). Chocó I: Introduction and bibliography. International Journal of American Linguistics. 29 (3), 239-63.

Morínigo, M. (1966). Diccionario de americanismos. Buenos Aires: Muchnik editores.

Morínigo, M. (1998). Nuevo diccionario de americanismos e indigenismos. Buenos Aires: Editorial Claridad.

Martínez-Mauri, M. (2011). La autonomía indígena en Panamá: la experiencia del pueblo kuna (siglos XVI- XXI). Quito: Ediciones Abya-Yala.

Nebrija, A. (1951 [1494]). Vocabulario español-latino. [Edición facsímil digital de la Real Academia Española], Madrid: [s.n.].

Pérez-Aguilar, R.A. (2001). Indigenismos en el español hablado en Chetumal. En: Estudios de Lingüística y Literatura. (27-44). México: Sans Serif Editores.

Pichardo, E. (1836). Diccionario provincial de voces cubanas. Matanzas: Imprenta de la Real Marina.

Price, K. (2005). Kuna or Guna?: The linguistic, social and political implications of development a standard orthography. (Tesis de Maestría). The University of Texas.

Quesada-Pacheco, M.Á. (2007 [1991]). Nuevo Diccionario de Costarriqueñismos. Cartago: Editorial Tecnológica de Costa Rica.

Real Academia Española. (1984 [1726-1739]). Diccionario de Autoridades. Madrid: Gredos.

Real Academia Española. (2001). Diccionario de la Real Academia Española. Madrid: Espasa.

Richard, R. (1997-2006). Diccionario de hispanoamericanismos no recogidos por la Real Academia. Madrid: Cátedra.

Romoli, K. (1987). Los de la lengua Cueva: las tribus del istmo oriental al tiempo de la conquista española. Bogotá: Instituto Colombiano de Antropología.

Tejera, M.J. (1993). Diccionario de venezolanismos. Caracas: Universidad Central.

Santamaría, F. (1942). Diccionario general de americanismos. México: Editorial Pedro Robredo. 
Valle, A. (1948). Diccionario del habla nicaragüense. Managua: Editorial La Nueva Prensa.

Wafer, L. (1695 [1704]). A new voyage and description of the Isthmus of America. Londres: James Knapton.

Wafer, L. (1695 [1729]). The voyages of Lionel Wafer. Por W. Dampier. A collection of voyages. Vol. II. Londres: James Knapton.

Werner, R. (2001). Áreas pendientes de la lexicografía del español americano. II Congreso Internacional de la Lengua Española: El español en la Sociedad de la Información. Valladolid, España. http://congresosdelalengua.es/valladolid/ponencias/ [Consulta: 12 de setiembre de 2013]. 
